\title{
A network of p73, p53 and Egr1 is required for efficient apoptosis in tumor cells
}

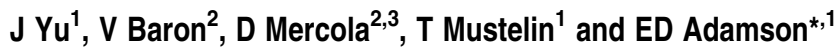

p73, a transcription factor rarely mutated in cancer, regulates a subset of $\mathrm{p} 53$ target genes that cause cells to respond to genotoxic stress by growth arrest and apoptosis. p73 is produced in two main forms; only TAp73 reiterates the roles of p53, while $\triangle N$ p73 can be oncogenic in character. We show that the TAp73 form produced by TP73 P1 promoter has five distinct Egr1binding sites, each contributing to the transcriptional upregulation of TAp73 by Egr1 in several cell types. In contrast, TP73 P2 promoter transcribes $\Delta \mathrm{Np} 73$, is not induced by Egr1, but is induced by TAp73 and p53. Induction of TAp73 by genotoxic stress requires Egr1 in mouse in vivo. Newly discovered non-consensus p53-binding sites in p73, p53 and Egr1 promoters reveal interregulating networks and sustained expression by feedback loops in response to stress, resulting in prolonged expression of the p53 family of genes and efficient apoptosis.

Cell Death and Differentiation (2007) 14, 436-446. doi:10.1038/sj.cdd.4402029; published online 22 September 2006

Egr1 (early growth response 1), also known as NGFI-A, ZIF268, Krox24, or TIS8) has been endowed with the ability to function in numerous capacities, including differentiation, ${ }^{1}$ growth; ${ }^{2}$ growth inhibition ${ }^{3,4}$ and apoptosis ${ }^{5}$ depending on the cell type and the stimulus. The Egr1 gene is characterized by its rapid and transient upregulation in response to numerous stresses. In addition, Egr1 upregulates the transcription of the p53 promoter to induce the apoptosis of cancer cells. ${ }^{6}$ Thus, in response to stress, Egr1 displays a remarkable functional similarity to p53 and p73. For instance DNA-damaging chemotherapy leads to growth arrest and imperfect DNA repair that may be followed by programmed cell death (apoptosis). To provide this responsiveness, the most important gene is TP53, a tumor suppressor gene. However, TP53 is frequently mutated and its protein product, p53mut, has altered activities in cancer cells. ${ }^{7}$ Then, stress responses fall on the related gene TP73 that has similar features to TP53 with some distinctions. There are large differences in the protein products of the TP73 gene compared with TP53, in their promoters and by alternate splicing of exons that lead to the production of 17 different proteins for TP73 (reviews $^{8-10}$ ).

TP73P1 promoter produces a set of transcription-activating forms named TAp73. Promoter P2 produces $\Delta$ Np73 forms that were thought to have non-transactivating roles although they now appear to have transcriptional activity on target genes that give rise to both anti-apoptotic ${ }^{11-13}$ and proapoptotic activities. ${ }^{14,15}$ It was noted earlier that $\Delta \mathrm{Np} 73$ protein acts as a dominant negative of p53 action on its target genes $^{16}$ through the oligomerization of the $\Delta \mathrm{Np} 73$ subunits with $\mathrm{p} 53$ or TAp73 subunits. ${ }^{17}$
A search for EBS and p53BS in the regulatory regions of the p53 family of genes revealed novel, specific, non-consensus p53 responsive elements (RE) in the p53 and Egr1 promoters that are bound and transactivated by the p53 family members including $\Delta \mathrm{Np} 73$ forms. Egr1 can now be classified as a key transcriptional regulator of this group of genes. Moreover, we show that the promoters of Egr1, TP53 and TP73 all respond to Egr1, p53, TAp73 and $\Delta$ Np73 proteins and elicit feedback loops between these four genes. In contrast, the p63 member of the p53 gene family does not respond to Egr1 and lacks Egr1-binding sites (EBS) in its promoter.

The existence of the regulatory network described here is important because the most effective function of tumor suppressor genes in cancer cells is to activate apoptosis. The versatility of this cross-regulation permits a wide range of graded responses of cells to stresses such as radiation and chemotherapy, a finding with therapeutic implications.

\section{Results}

Cells that differentially express Egr1, p53 and p73 exhibit different sensitivities to etoposide. Three different types of cancer cell lines were used to measure levels of apoptosis following treatment with the chemotherapeutic drug etoposide (ETO). Only $20 \%$ of MCF7 breast cancer cells died compared with $80 \%$ in $\mathrm{M} 12$ prostate cancer cells and U2OS osteosarcoma cells (Figure 1a). Each of these cell lines expresses different levels of Egr1, p53 and p73 proteins as indicated below the graph. MCF7 cells express the lowest protein levels

\footnotetext{
${ }^{1}$ Burnham Institute for Medical Research, Cancer Research Center, La Jolla, CA 92037, USA; ${ }^{2}$ Sidney Kimmel Cancer Center, San Diego, CA 92121, USA and ${ }^{3}$ Pathology and Laboratory Medicine, University of California at Irvine, Irvine, CA 92697-4800, USA

${ }^{*}$ Corresponding author: ED Adamson, The Burnham Institute, 10901 N. Torrey Pines Road, La Jolla, CA 92037, USA. Tel: +1 8586463100 X3650;

Fax: + 1858646 3198; E-mail: eadamson@burnham.org

Keywords: Egr1; p73; p53; transcription regulation; feedback loops; chromatin immunoprecipitation; Egr1 knockout mice

Abbreviations: ChIP, chromatin immunoprecipitation; EBS, Egr1 binding site; ETO, Etoposide; MEFs, mouse embryo fibroblasts; RE, responsive element; RT-PCR, real-time polymerase chain reaction; TAD, transcription activation domain; UV-C, ultraviolet radiation at $254 \mathrm{~nm}$

Received 16.2.06; revised 10.7.06; accepted 11.7.06; Edited by V De Laurenzi; published online 22.9.06
} 


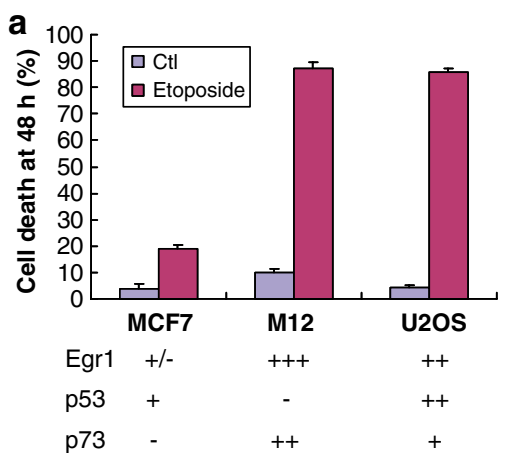

b Mouse study
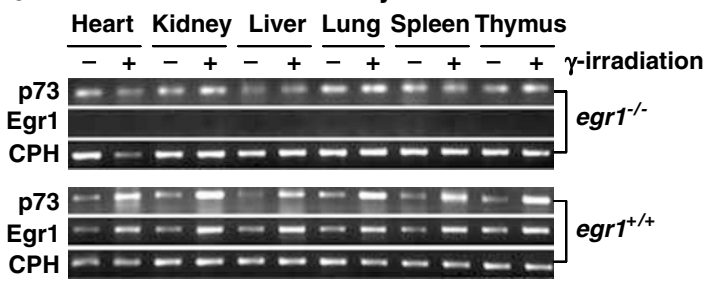

Figure 1 Genotoxic stress leads to apoptosis in cell lines and to increased Egr1 and p73 expression in vivo. (a) MCF7 breast, M12 prostate and U2OS fibrosarcoma cells induced with ETO $(20 \mu \mathrm{g} / \mathrm{ml})$ chemotherapy drug, show induced apoptosis levels consistent with the additive expression of Egr1, p53 and p73. (b) Tissues dissected from $\left(\mathrm{Egr}^{+/+}\right)$or knockout $\left(\mathrm{Egr}^{-1-}\right)$ mice $2.5 \mathrm{~h}$ after gamma-irradiation at $5 \mathrm{~Gy}$, were analyzed by semiquantitative RT-PCR to reveal the induction of Egr1 and p73 mRNAs. One example is shown of duplicate studies that gave similar results
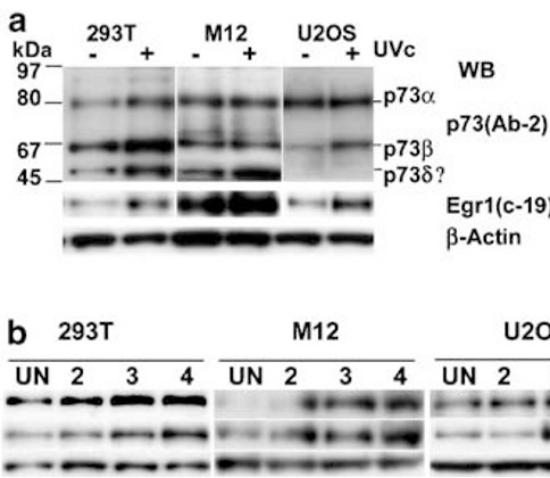

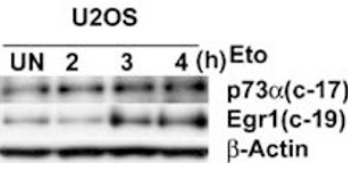

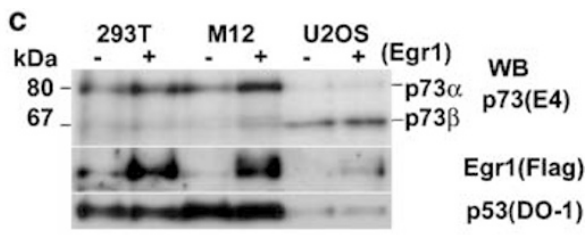

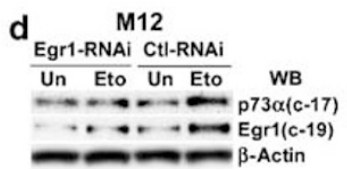

Figure 2 Immunoblots indicate that Egr1 and p73 are induced by UV irradiation or ETO treatment of a variety of cell types. (a) UVc irradiation (40 J/M²) of three cell types induced Egr1 and p73 protein isoforms measured $4 \mathrm{~h}$ later. (b) ETO $(20 \mathrm{~g} / \mathrm{ml})$ added to three cells types induced Egr1 and p73 $\alpha$ in a time-course study. (c) Transfection of an Egr1 expression plasmid into three cell lines induced $p 73 \alpha$ and $\beta$ protein isoforms. (d) Egr1 RNAi reduces the induction of Egr1 and p73 $\alpha$ in ETO treated M12 prostate cancer cells, while a control RNAi has no effect

compared with the other two cell lines, correlating with lower apoptosis levels.

Egr1-null mice fail to induce p73 in response to radiation. Mice with Egr1 inactivated by homologous recombination $\left(\mathrm{Egr}^{-/-}\right)$or wild-type (WT) $\left(\right.$Egr $\left.1^{+/+}\right)$were analyzed for p73 expression $2.5 \mathrm{~h}$ following $\gamma$-irradiation (5Gy). Mice were killed and the mRNA levels of six tissues were measured by semi-quantitative real-time-polymerase chain reaction (RT-PCR). We show in Figure $1 \mathrm{~b}$ that irradiation-induced Egr1 in the WT mouse was accompanied by increased p73 mRNA in all tissues. The presence of Egr1 was required since the Egr1-null tissues showed no irradiation-induced p73. Instead, p73 levels were somewhat reduced. We previously observed that p53 expression is absent in Egr1 ${ }^{-/-}$MEF (mouse embryo fibroblasts). ${ }^{18,19}$ Thus, Egr1 appears to be required for induction of both p53 and $\mathrm{p} 73$.

Promoter upregulation by Egr1 results in p73 protein expression. As p73 occurs in many isoforms, we determined which forms are accumulated as a result of promoter transactivation by Egr1. In 293T cells, M12, and U2OS cells treated with UV to induce Egr1 (Figure 2a), three p73 isoforms ( $\alpha, \beta$ and $\delta$ ) were induced to varying levels. In M12 prostate cells, only $\mathrm{p} 73 \delta$ was upregulated while in U2OS cells, only $\mathrm{p} 73 \beta$ was induced. Clearly, expression levels and isoform of p73 that are upregulated upon Egr1 induction depend on the cell line. In Figure 2b, Egr1 and p73 protein levels were measured at increasing times of ETO treatment. In 293T cells, Egr1 protein remained elevated for $2-4 \mathrm{~h}$ after treatment and $p 73 \alpha$ was elevated accordingly. Similarly, the addition of an Egr1 expression vector increased the expression of p73 in three cell lines tested (Figure 2c). We conclude that Egr1 regulates p73 expression following genotoxic stress. Vector-based Egr1-RNAi reduced Egr1 expression and inhibited ETO-induced levels of $\mathrm{p} 73 \alpha$ (Figure 2d).

\section{Egr1 upregulates the transcription of the TAp73gene but} not the $\Delta \mathrm{Np73}$ form. We constructed luciferase reporter pGL3-TAp73 containing TP73 P1 promoter. The P1 promoter contains five potential high-affinity EBS named $a, b, c, d$ and e (Supplementary Figure S1). Promoter P2 was cloned into pGL3 to serve as a reporter gene for $\Delta \mathrm{Np} 73$ isoforms and contains a single EBS (named $\mathrm{f}$ ). Transfection of pGL3TAp73 into 293T cells together with expression plasmids for Egr1 shows that Egr1 transactivated both promoters by 
a
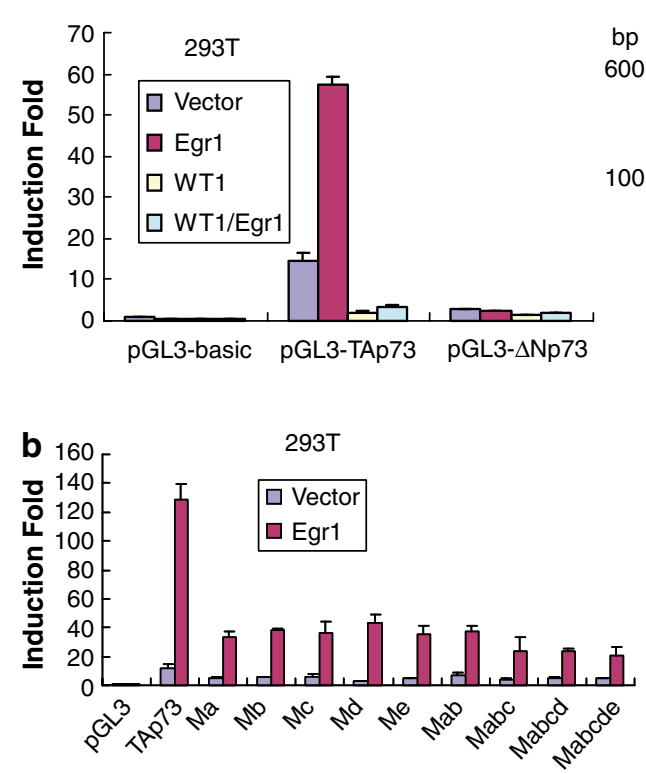
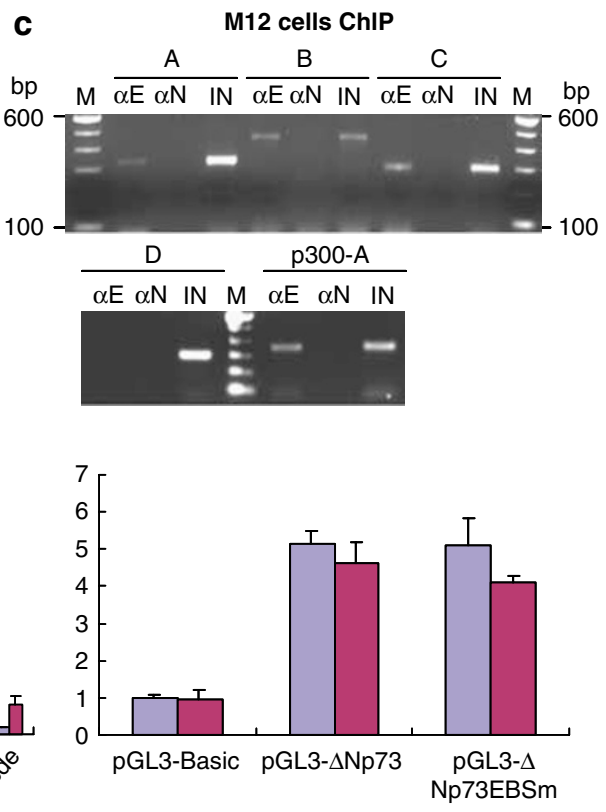

Figure 3 TAp73 promoter (P1) binds Egr1 and is upregulated; the $\Delta$ Np73 promoter (P2) does not respond to Egr1 (see Supplementary Figure S1). (a) TAp73 promoter luciferase reporter is strongly induced by Egr1 but not by the related WT1 protein or by a dominant negative expression vector WT1/Egr1 measured $24 \mathrm{~h}$ after transfection. (b) Mutation of each of the five EBS showed that all sites are activated by Egr1 expression. In contrast, Egr1 did not transactivate the $\triangle$ Np73 promoter or the mutated EBS in the $\Delta$ Np73 promoter. Triplicate results were in close agreement and were averaged for all the transcription studies presented here. (c) ChIP confirmed this result. The DNA captured by $\alpha$ Egr1 $(\alpha \mathrm{E})$ was purified and compared by PCR analyses on DNA captured from non-immune $\lg (\alpha \mathrm{N})$ as a negative control and also compared with input DNA (IN) purified from the cells as a positive control

four- to 12-fold compared with the empty expression vector (pcDNA) (Figure 3a and Supplementary Figure S2). As a control a 'dominant negative' Egr1 vector, WT1/Egr1 and WT1 (Wilm's Tumor protein1) that binds to the same EBS sequences, had a negative effect on promoter activity. In contrast, there was no significant difference in the luciferase activity of the P2 promoter reporter pGL3- $\Delta$ Np73 following transfection of pcDNA-Egr1, indicating that this promoter is not activated by Egr1. We confirmed this by mutating the putative EBS in P2 (Figure $3 \mathrm{~b}$, right) and each of the five EBS in $\mathrm{P} 1$ by individual and combined mutations (Figure 3b, left). Each mutated Egr EBS similarly reduced the promoter activity by an average of $75 \%$. Only mutation of all five sites reduced the activity of the reporter gene by $85 \%$ although there was still some residual activity in P1 when all EBS were mutated. This analysis clearly shows that Egr1 upregulates the $\mathrm{P} 1$ promoter and may play a role in graded responses of TAp73 governed by the expression level of Egr1 in the cell.

We applied chromatin immunoprecipitation (ChIP) to M12 cells to confirm that Egr1 is directly bound to the promoter during transactivation. The results of ChIP (Figure 3c) confirm that Egr1 was bound to DNA fragments A, B and C, but not to $\mathrm{D}$, which is the inactive EBS in P2. As a positive control, ChIP detected p300, a known Egr1 target gene. ${ }^{20}$ In summary, Egr1 binds to and transactivates the TAp73P1 promoter but not the $\triangle$ Np73 P2 promoter.

P1 and P2 promoters of TP73 respond differentially to p53 and p73 proteins. We identified a new putative p53 RE (p53RE, Supplementary Figure S1) in the P1 promoter that was tested in 293T cells using a pGL3-TAp73 reporter transfected with vectors coding for $\mathrm{p} 53, \mathrm{TAp} 73 \alpha \beta$ or $\Delta \mathrm{Np} 73 \alpha, \beta$ (Figure 4a). The known p53RE in the P2 promoter of $\Delta \mathrm{Np} 73$ was far more responsive to p53 (80fold) than the P1 promoter. We also observed that TAp73 $\alpha$ and $\beta$ strongly induced the single p53RE in P2, while $\Delta N p 73$ had no effect on its own promoter. When examined on a magnified scale (Figure 4b), TAp73 $\alpha$ induction of the P1 promoter was threefold higher than the vector. p53 induction was weak but statistically significant, with $P<0.0038$ compared with empty vector. When the single p53RE in the P1 promoter was mutated (pGL3-TAp73REm) we observed that the activity of $\operatorname{TAp} 73 \alpha$ and $\beta$ was nearly abolished (Figure 4b, right). ChIP studies in ETO-treated U2OS cells confirmed that the p53RE-containing portions of P1 and P2 promoters bind to p53 and p73 (Figure 4c). We conclude that several p53 family proteins bind directly to the putative p53REs to effect and perpetuate transactivation within the family.

The Egr1 promoter is upregulated by Egr1, p53, TAp73 and $\Delta$ Np73. The Egr1 promoter contains active EBS. ${ }^{20}$ In addition, we identified four possible p53 REs (p53RE A1 to A4) in the non-coding sequences from $-2 \mathrm{~kb}$ to +142 of the promoter and 5'UTR (Supplementary Figure S3). A reporter construct in pGL3 termed 'Egr1' contains all four p53 sites while 'Egr1F' contains additional flanking sequences. Fragments of the promoter named Egr1P1, Egr1P2 and Egr1P3 were cloned into pGL3 and co-transfected into 293T cells with either $\mathrm{p} 53, \mathrm{TAp} 73$ or $\Delta \mathrm{Np} 73$ expression vectors. All promoters were activated similarly (2- to 2.5 -fold) by TAp73 

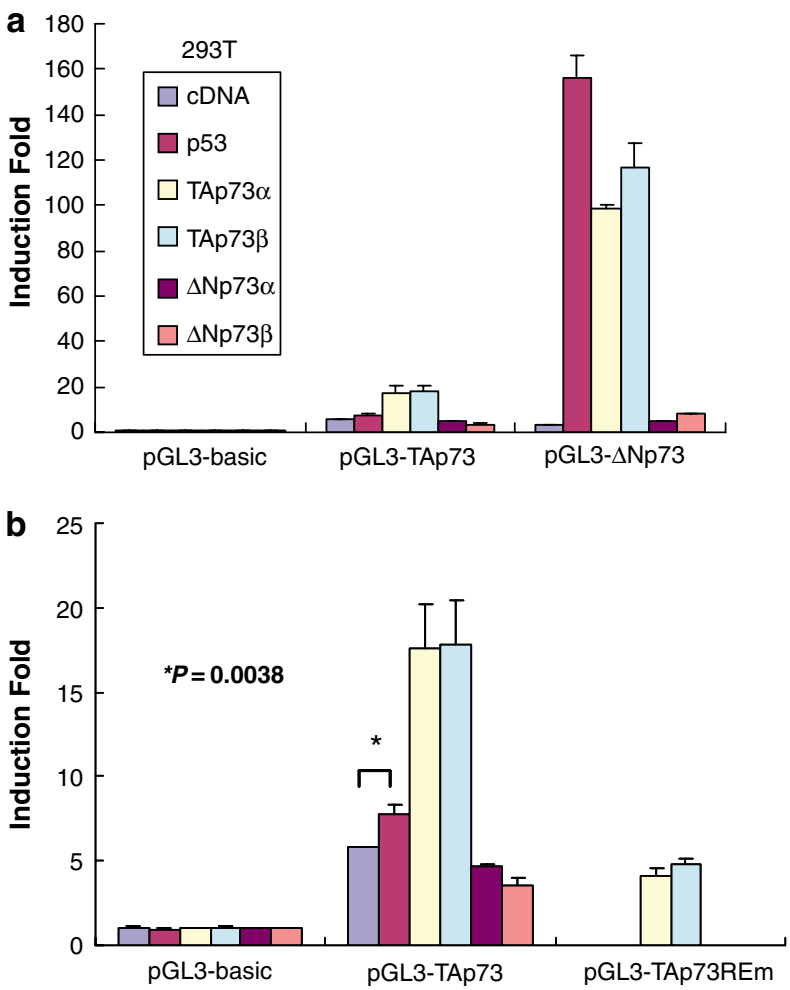

C

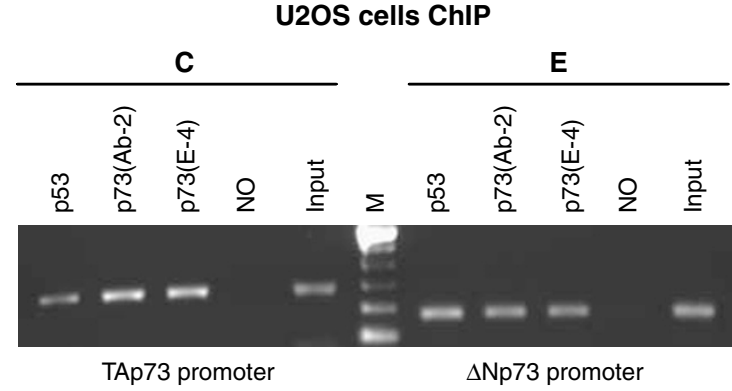

Figure 4 Analysis of the p53 REs in TAp73 and $\triangle N p 73$ promoters. (a, b). The pGL3-TAp73 and pGL3- $\Delta$ Np73 promoters, $\mathrm{P} 1$ and $\mathrm{P} 2$, respectively (structures are shown in the Supplementary Figure S1) were transfected into 293T cells to measure the luciferase signal $24 \mathrm{~h}$ later. Each promoter was tested for the effects of the expression of $\mathrm{p53}, \mathrm{TAp} 73 \alpha, \mathrm{TAp} 73 \beta, \Delta \mathrm{Np} 73 \alpha$ and $\Delta \mathrm{Np} 73 \beta$ after co-transfection. The P1 promoter was weakly responsive to TAp73 (see replot in b), while $\Delta$ Np73 expression was inhibitory. In contrast, the $\mathrm{P} 2$ promoter was 60 - to 80 -fold induced by $p 53$ and by TAp73, but not by $\Delta N p 73$. The right panel of $\mathbf{b}$ shows that the mutation of the p53RE in the P1 promoter reduces activity threefold. (c) ChIP confirmed that p53 and p73 proteins bind directly to the p53RE in intron $1(\mathrm{P} 1)$ as well as to the p53RE in intron 2 (P2) in U2OS cells treated with ETO for $6 \mathrm{~h}$ before cross-linking (NO is the negative control)

and $\Delta$ Np73 whereas p53 was half as active (Figure $5 \mathrm{a}$ and Supplementary Figure S4). Thus, all members of the p53 family induce the Egr1 promoter albeit to different degrees. The most effective reporter was Egr1P3 that contains only A2 and A3 p53RE.

To determine whether transactivation results in increased Egr1 protein levels, we performed immunoblots of $\mathrm{M} 12$ prostate cancer cells (contain inactive p53; Figure $5 \mathrm{~b}$ ) and MCF7 breast cancer cells (WT p53; Supplementary Figure S5), after transfection with expression vectors HA-tag
$\Delta \mathrm{Np} 73 \alpha, \mathrm{TAp} 73 \alpha$ or $\mathrm{p} 53$. An increase of Egr1 protein was observed in both cell types. ChIP experiments confirmed that p53 and p73 are specifically bound to Egr1 promoter in U2OS cells. Of the four putative p53RE, only p53A2 and p53A3 were bound (Figure $5 \mathrm{c}$ ). Thus, only two sites are directly involved in transcriptional activation of Egr1 in vivo. We therefore mutated these two active p53RE in the corresponding pGL3-Egr1 luciferase reporter construct (Figure 5d). Cotransfection with plasmids expressing p53, TAp73 or $\Delta \mathrm{Np} 73$ displayed reduced transactivation of p53RE-A2m and $A 3 m$ compared to the WT promoter. p53RE-A3 was the most affected by mutation, which reduced promoter activity by sixto eightfold for all p73 isoforms. These results prove that two new p53RE in Egr1 promoter are responsive to all members of the p53-family of proteins, resulting in increased Egr1 protein levels.

We next tested p73 isoforms for their ability to induce the Egr1 promoter, to assess the role of p73 transactivating domain (TAD). TAp $73 \alpha$ and $\Delta \mathrm{Np} 73 \alpha$ each induced Egr1 transcription by $\sim 3$-fold even though $\Delta \mathrm{Np} 73 \alpha$ lacks a recognizable TAD (Figure $5 \mathrm{e}$ ). However, the $\mathrm{N}$-terminal domains of TAp73 and $\triangle \mathrm{Np} 73$ are required, because expression of TAp73 $\Delta 1-62$ ( $\triangle T A D)$ and $\Delta 1-127$ $(\triangle \mathrm{TAD}+\triangle \mathrm{PXXP}$ domains) failed to transactivate the Egr1 promoter. Deletion of the unique 13 amino acids $\mathrm{N}$-terminal of $\Delta \mathrm{Np} 73$ indicated that it is required to transactivate the Egr1 promoter and therefore acts as a TAD. Deletion of the PXXP motif in $\Delta \mathrm{Np} 73 \Delta 1-78$ made no further difference, indicating that the 13 amino-acid sequence is the crucial requirement for transactivation of Egr1 promoter.

p53 transcription is upregulated by p53 family members. We tested the DNA sequence between -764 and +229 of human TP53 for transactivation in pGL3-p53 reporter constructs (Supplementary Figure S6A and C). One EBS and three p53RE sites (p53F, p53M and p53Z) in TP53 promoter have not been previously described. The $0.9 \mathrm{~kb}$ p53 promoter reporter was not induced by Egr1 in $\mathrm{H} 4$ cells (Supplementary Figure S7-left), but was induced by Egr1 as well as by WT1 and WT1/Egr1 in 293T cells (Figure 6a) and in Saos2 (Supplementary Figure S7-right). It is unusual that both WT1 and Egr1 transactivate TP53 promoter equally well, when they usually have opposite effects on other target genes. In contrast, p53 induced TP53 promoter by threeto ninefold, depending on the cell line and the size of promoter sequences used (Figure $6 \mathrm{~b}$ and Supplementary Figure S6B, C and S8). The binding sites $F$ and $M$ contain CTG-CAG trinucleotide repeats that form hairpin structures (Supplementary Figure S6C) and form strong bonds with p53. ${ }^{21}$ In 293T cells, TP53 promoter was strongly induced by TAp73 $\alpha$ and $\beta$ but to a lesser extent by $\Delta \mathrm{Np} 73 \alpha$ and $\beta$ (Figure $6 \mathrm{~b}$ and Supplementary Figure S8). The induction of TP53 transcription by 153 was also concentration-dependent in both 293T and Saos2 cells (Supplementary Figure S9) indicating that the transcription factor expression level plays a major role in the strength of the transactivation.

We tested the binding of the three proteins to TP53 promoter by ChIP in U2OS cells (Figure 6c). Only p53F and p53M sites were bound to, while p53Z did not bind any of the three proteins (Figure $6 \mathrm{c}$ ). We confirmed the transactivating 


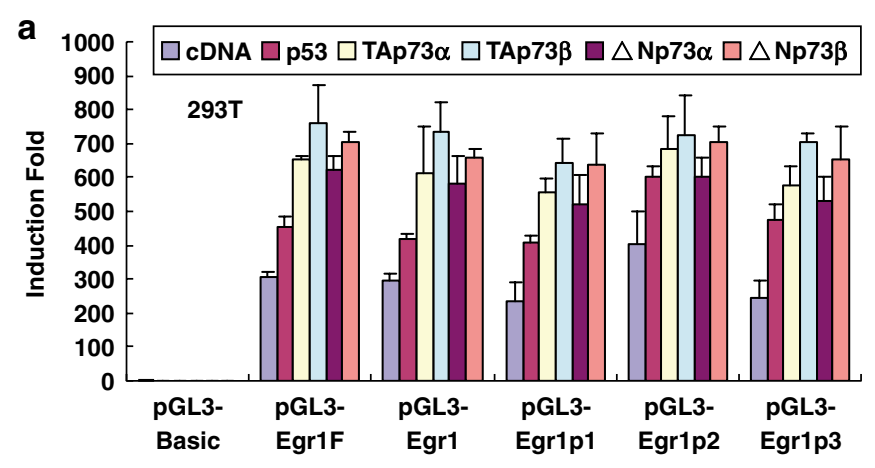

b

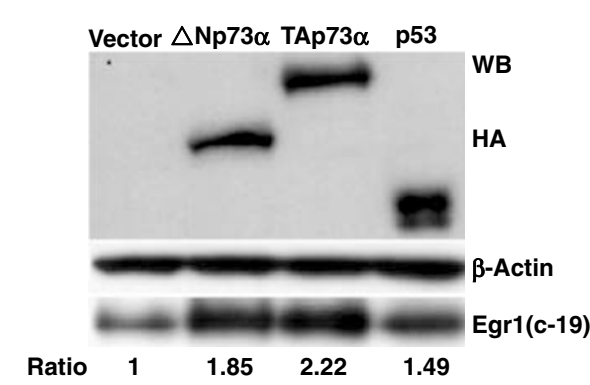

d

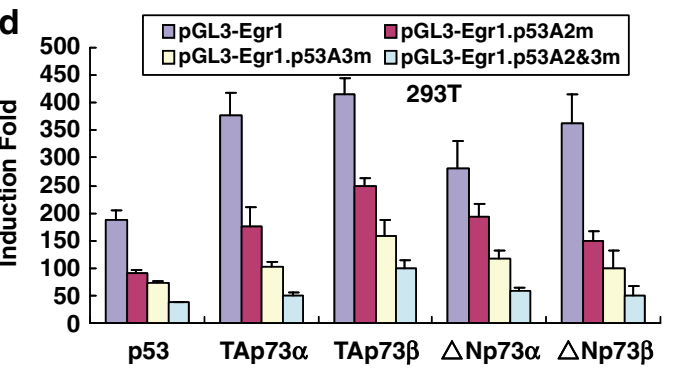

C U20S cells ChIP

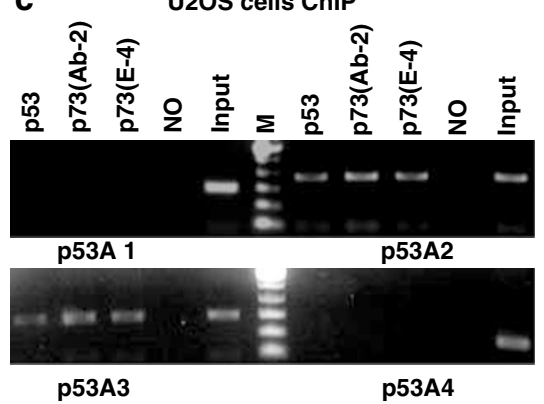

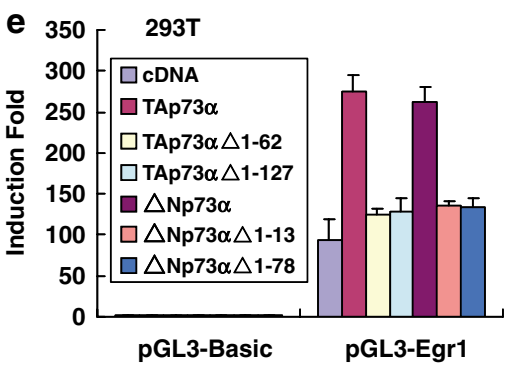

Figure 5 All members of the p53 family induce the Egr1 promoter by binding to two p53BS (see Supplementary Figure S3 for the structure and features of the Egr1 promoter). (a) The transactivation of the Egr1 promoter in 293T cells was studied using pGL3-Egr1. The Egr1 promoter was tested as five different fragments (Egr1, Egr1F, Egrp1, Egr1p2 and Egr1p3). TAp73 $\beta$ and $\Delta N p 73 \beta$ isoforms were the most active ( $>2$-fold); the least active was p53. The Egr1F and Egr1 promoter fragments each carry four putative p53BS, but there was little difference in the fold increase in transactivation between the five different Egr1 promoter forms. (b) Immunoblot of Egr1 produced by expression vectors of the $\mathrm{p} 53$ family transfected into M12 cells. (c) ChIP was used to validate the transactivation result by showing that only two (A2 and A3) of the four putative p53RE were bound to their transactivator p53 family proteins. (d) Mutation of the A2 and A3 binding sites, singly or doubly clearly show that both sites are transactivating when not mutated, with $\mathrm{A} 3$ the most active p53RE. (e) wt TAp73 and $\triangle \mathrm{Np} 73$ are equally active in up-regulation of the Egr1 promoter; in contrast $\mathrm{N}$-terminal deletions of the expressed p73 proteins, TAp73 $\alpha \Delta 1-62$ and 1-127, $\Delta \mathrm{Np} 73 \alpha \Delta 1-13$ and 1-78 are unable to induce the Egr1 promoter

function of these sites by mutational analysis of the promoter (Figure 6d). Only mutation at both p53F and p53M maximally inhibited transactivation of the pGL3-p53 reporter construct by TAp73 $\alpha, \beta, \Delta \mathrm{Np} 73 \alpha$ and $\beta$. The deletion mutants described in Figure $5 \mathrm{e}$ were also used to test their ability to transactivate the TAp73 and $\triangle N p 73$ promoter-reporters by transfection into 293T cells. Figure 6e shows that TAp73 induced TP53 promoter sixfold, and $\Delta \mathrm{Np} 73$ induced it twofold. Deletion mutants of TAp73 ( $\Delta 1-62$ and $\Delta 1-127)$ or $\Delta N p 73(\Delta 1-13$ and $\Delta 1-78)$ clearly reduced TP53 transactivation in a step-wise manner, indicating a requirement for both the TAD and PxxP motifs. In contrast, the $\triangle N p 73$ promoter was activated only by intact TAp73 (Figure 6e). These studies show that the p53 protein is a functional transactivator of its own promoter in vivo.
Induction of Egr1 expression by ETO follows a timecourse consistent with positive feedback via p73 and p53. We measured mRNA and proteins expressed during a time-course of ETO treatment. Figure $7 \mathrm{a}$ shows the timecourse of Egr1 mRNA (left) and p53 mRNA (right) measured by qRT-PCR after ETO addition to MCF7 cells, in presence or absence of p53-RNAi. Egr1 mRNA level increased 26-fold at $1 \mathrm{~h}$, peaked at $3 \mathrm{~h}$ before declining to a constant 10 -fold induction for up to $11 \mathrm{~h}$. In the presence of p53-RNAi, Egr1 levels were severely reduced. Levels of p53 mRNA increased in two peaks at 1 and at $11 \mathrm{~h}$ but were inhibited by p53-RNAi. A control RNAi gave the same results as Mock (data not shown). Figure $7 \mathrm{~b}$ shows protein levels after immunoblotting. Interestingly, there were two peaks of Egr1 at 1 and $8 \mathrm{~h}$ while $p 53$ peaked at $2 \mathrm{~h}$ and remained constant. 
a

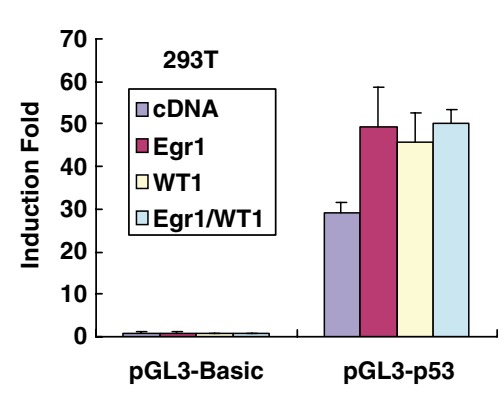

b

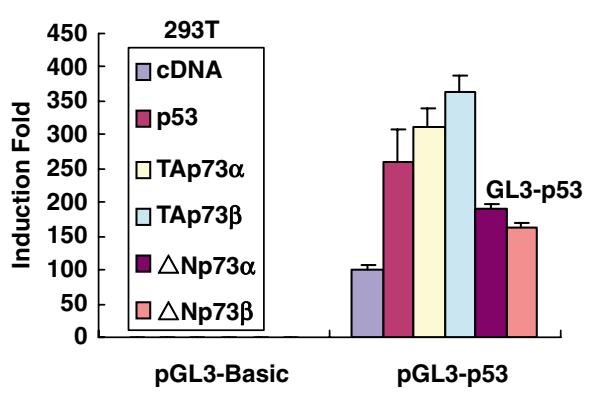

C U2OS cells ChIP

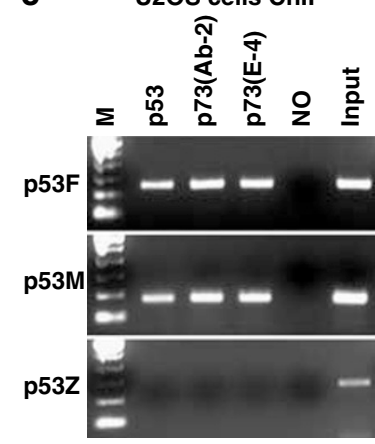

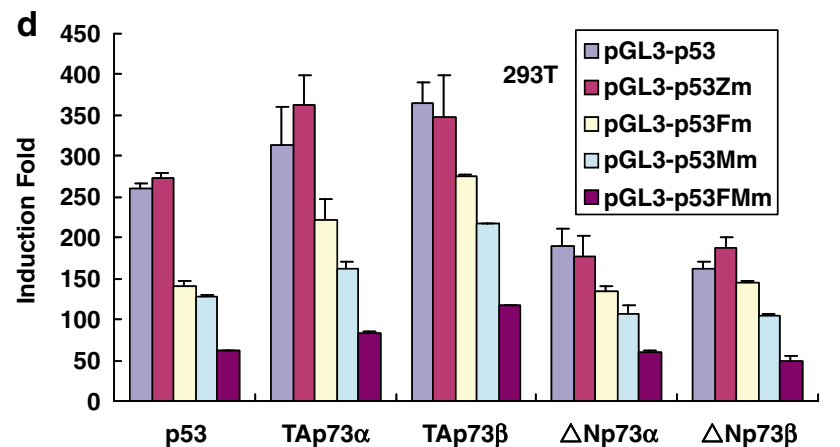

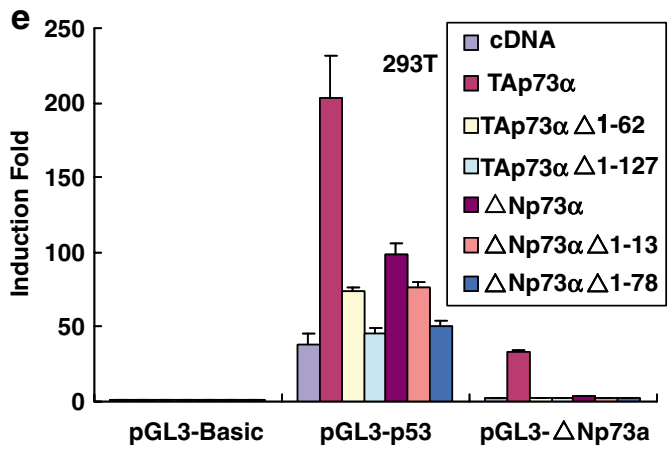

Figure 6 The p53 promoter is differentially activated by Egr1, and by p53, TAp73, $\Delta$ Np73 at two p53BS. (see Supplementary Figure S6A for details of the structure of the promoter). (a) In $293 \mathrm{~T}$ cells, transiently-expressed Egr1, WT1 and the dominant negative WT1/Egr1 all weakly induce the p53 promoter, (b) transfection of expression plasmids for the five members of the p53 family each induced the p53 promoter to different extents depending on the cell line. (c) ChIP was used to detect binding of the p53 and $p 73$ proteins at the two of the three putative p53RE ( $F, M$, positive binding) and (Z, no binding). The $Z$ site is not responsive while both the $F$ and $M$ binding sites are required for p53 promoter responses to p53 and TAp73 and $\Delta$ Np73. (e) The same deleted forms of the expressed p53, TAp73 and $\triangle N p 73$ proteins as used in Figure $5 e$ indicate that the amino-terminal sequences of TAp73 and $\triangle \mathrm{Np} 73$ are required for transactivation

Use of phospho-specific antibodies against p53 phosphorylated at Ser46 (S46p-p53) indicated that p53 phosphorylation was high between 3 and $5 \mathrm{~h}$. When p53-RNAi was added before treatment, both Egr1 and p53 protein levels were reduced.

Consistent with these results, ChIP shows that $\mathrm{p} 53$ bound steadily to Egr1 promoter, as did S46p-p53 (Figure 7c). In addition, there was a small peak of p53 binding to TP53 promoter matching the mRNA increase of Figure 7a. Interestingly, the timing of p53 phosphorylation at Ser46 correlated with the decreased levels of Egr1 seen in Figure 7b.

In M12 cells (p53 inactive), Egr1 mRNA was induced at two peaks at $1-3 \mathrm{~h}$ and $7 \mathrm{~h}$. Egr1 transactivation was inhibited in the presence of $\mathrm{p} 73-\mathrm{RNAi}$, suggesting a feedback mechanism from p73 (Figure 7d-left). In contrast, p73 mRNA levels rose evenly to 4.5-fold after ETO treatment (Figure 7d-right) and this was completely eliminated by p73-RNAi. The changes in protein levels (Figure 7e) were less marked because both Egr1 and p73 are high in M12 cells. Egr1 expression peaked at 1 and $3 \mathrm{~h}$ while $\mathrm{p} 73$ was seen between 2 and $12 \mathrm{~h}$. Inhibition of p73 expression by p73-RNAi resulted in inhibition of Egr1 (Figure 7e). There was a clear difference in timing of promoter binding observed in ChIP (Figure 7f). Egr1 bound TAp73 promoter at all EBS at $2 \mathrm{~h}$ and again at $8 \mathrm{~h}$, while $\mathrm{p} 73$ bound to both p53RE (A2 and $A 3$ ) from 3 to $12 \mathrm{~h}$. Binding of p73 to the p53RE of the C portion of the Egr1 promoter followed a similar time-course. A similar analysis of U2OS cells is shown in Supplementary Data (Supplementary Figure S10). Thus, the expression of Egr1, p53 and p73 leads to a complex timing pattern.

In summary, Egr1 upregulates both p73 and p53, and Egr1 is itself upregulated by p53 and p73 in a feedback loop. This confirms earlier data that Egr1 induces the transcription of $p 53^{6,18}$ and that $p 73$ is regulated by $p 73$ and $p 53 .^{22}$ We conclude that there is a transcriptional inter-regulatory network between Egr1, p53 and p73. Our hypothesis is that Egr1 is the initial stress response gene that transactivates p73 and p53, which in turn create a network of positive feedback regulations.

Elevation of Egr1, p53 or p73 expression results in increased apoptosis. Figure 1a shows that ETO induced apoptosis in $80 \%$ of M12 and U2OS cells, but only in $20 \%$ of MCF7 cells, in which Egr1 and p53 are low and p73 is absent. This suggests that cooperation between the three proteins is required to achieve high levels of apoptosis. Increased expression of p53 (or p73) was required for high levels of apoptosis, which depended on the concentration of expression vector used (Supplementary Figure S9). Figure $8 \mathrm{a}$ shows that overexpression of Egr1, p53 or TAp73 increased apoptosis in U2OS cells, while $\Delta$ Np73 did not. Apoptosis further increased when two proteins were 

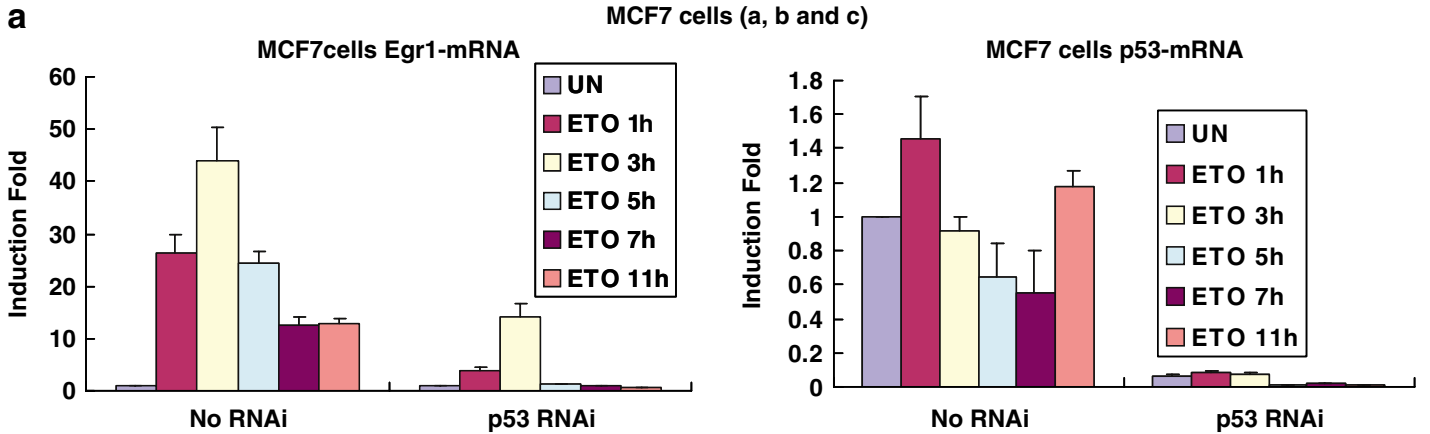

b

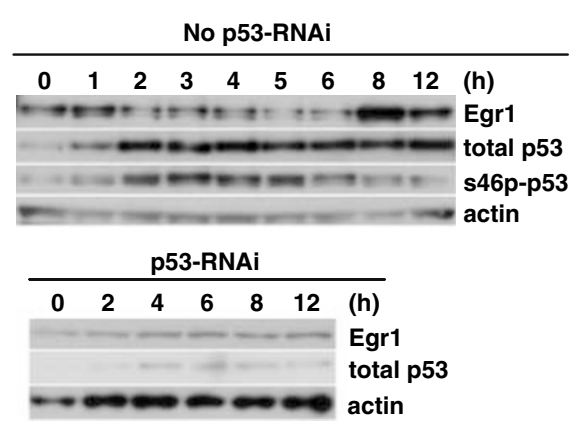

C
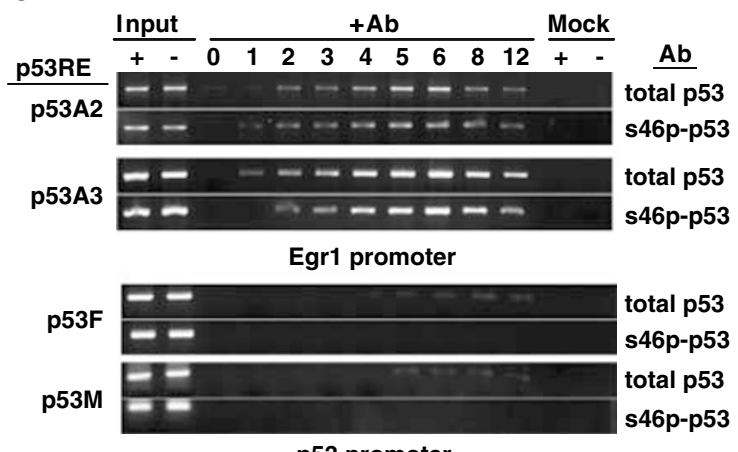

p53 promoter
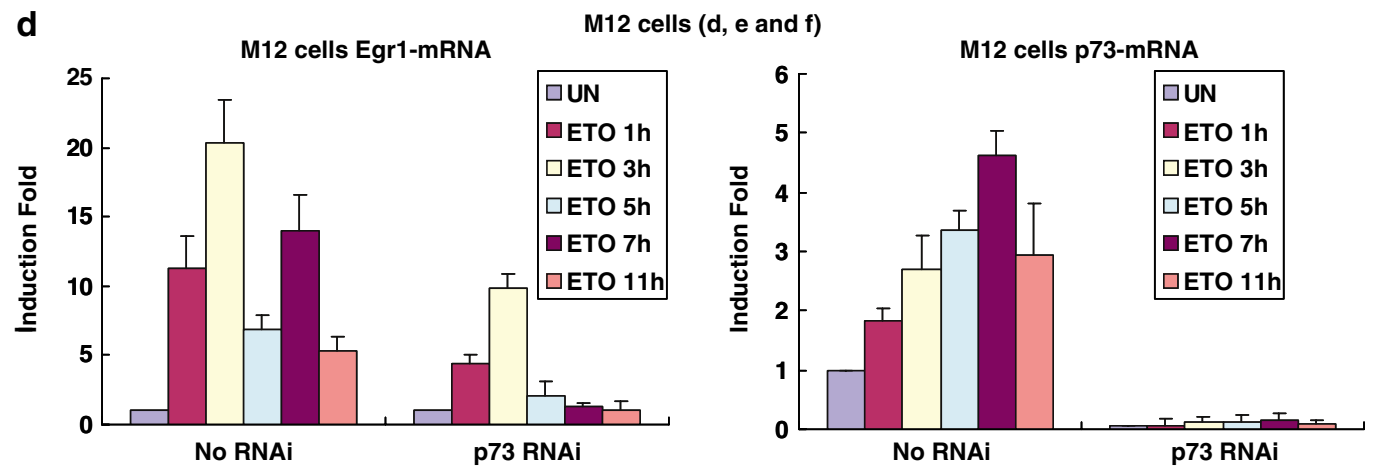

e
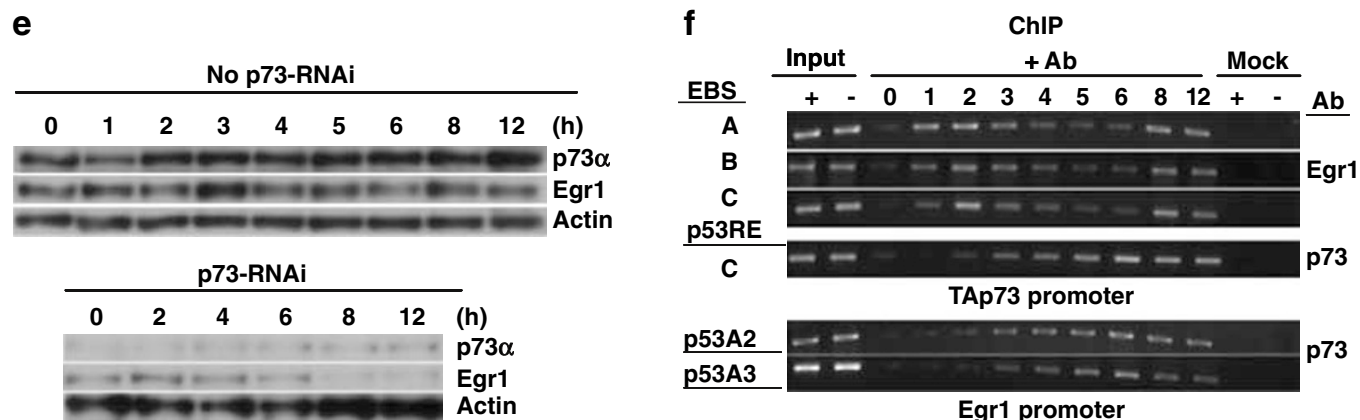

Figure 7 Two cell lines show differential expression of Egr1, p73 and p53 proteins during a time-course following ETO treatment. (a) MCF7 and (d) M12 cells show mRNA levels during the time-course. (b, e) Immunoblots using ECLplus, from MCF7 and M12 cells in the absence or presence of RNAi as shown, (c, f), ChIP studies on MCF7 and M12 cells show the differential binding of proteins to the relevant promoter fragments during the time-course. These are representative of at least two separate studies

co-expressed. RNAi to each protein decreased ETO-induced apoptosis (Figure $8 \mathrm{~b}$ : reduction of $30 \%$ with Egr $1-\mathrm{RNAi}, 20 \%$ with p53-RNAi).
Co-transfection of two and three RNAi further reduced apoptosis, indicating that expression levels of the three genes contribute to the level of apoptosis achieved. In ETO-treated 


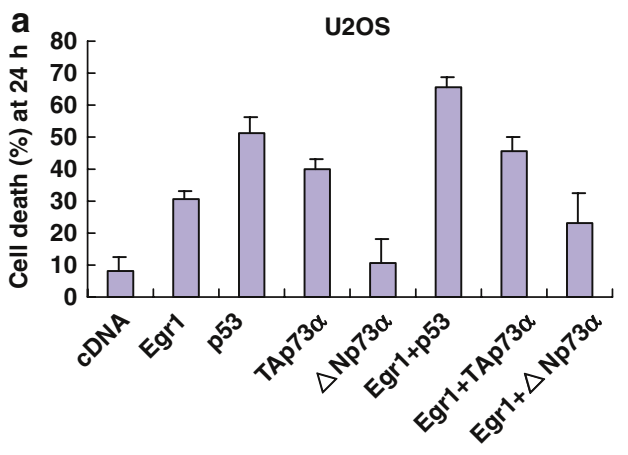

b

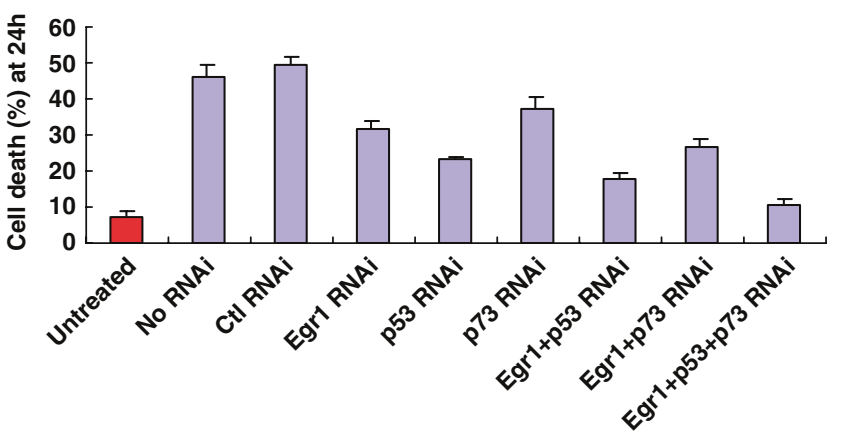

C

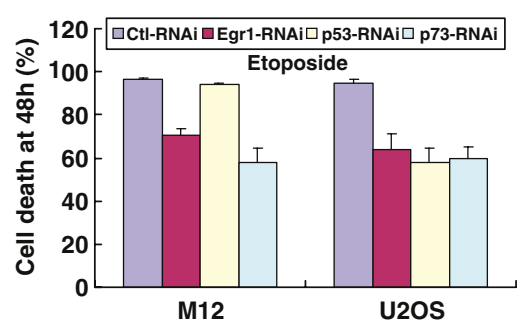

d

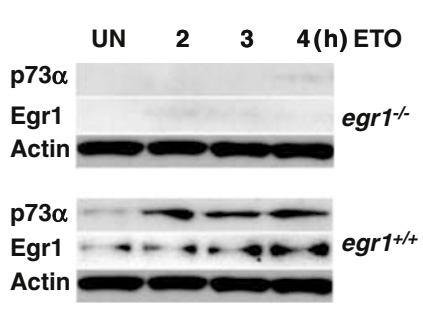

Etoposide treated U2OS

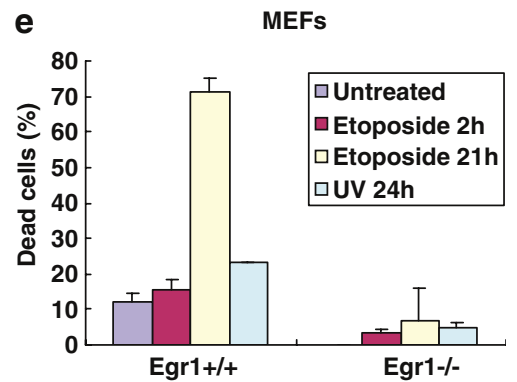

f

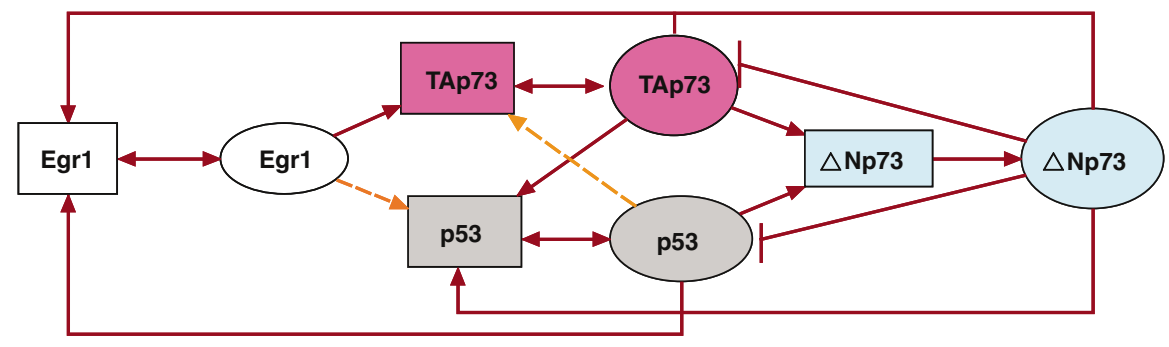

mRNA Protein

Figure 8 Apoptosis levels achieved by Egr1, p53 and p73 expression in several cell lines. The treated cultures were stained with Trypan blue to calculate the percentage of dead cells, in triplicate cultures repeated three times (a) U2OS cells transfected with Egr1 and /or p53 family members, (b) ETO-treated (20 $\mu \mathrm{g} / \mathrm{ml})$ U2OS cells were transfected with various RNAi, with measurement of apoptosis levels after $24 \mathrm{~h}$. (c) M12 and U2OS cells were treated with ETO and apoptosis measured after $48 \mathrm{~h}$. (d) Egr1 ${ }^{+1}$ ${ }^{+}$and ${ }^{-l-}$ MEFs were compared for the levels of proteins induced after addition of ETO during a time-course. (e) Egr ${ }^{-1-}$ and ${ }^{+/+}$MEFs treated with ETO or UV $\left(50 \mathrm{~J} / \mathrm{m}^{2}\right)$ indicate that Egr1 is required for apoptosis as measured by nuclear fragmentation. (f) Summary Figure showing the interactions of proteins and promoters that regulate p53, p73 and Egr1 described in this paper. Arrows denote strong transactivating activity, dashed arrows indicate weak activity, T-bars indicate blocked activity

M12 cells Egr1-RNAi or p73-RNAi, but not p53-RNAi, decreased apoptosis (Figure $8 \mathrm{c}$ ), consistent with the fact that p53 is inactive in these cells. Each RNAi achieved a 15-30\% reduction in apoptosis of U2OS cells.

Egr1 $^{+1+}$ and Egr1 ${ }^{-1-}$ MEFs ${ }^{23,24}$ were tested next, at late passage. Egr1 ${ }^{-1-}$ cells lack p73 as seen in Figure $8 \mathrm{~d}$ and lack p53 as described previously ${ }^{18}$ indicating that Egr1 is key to the interactive network between these genes. Figure $8 \mathrm{e}$ shows that in Egr1 ${ }^{+/+}$MEFs, ETO induced apoptosis in $70 \%$ of the cells and UV-C-induced apoptosis in $22 \%$ of the cells. In contrast, Egr1 $1^{-1-}$ cells showed little apoptosis, allowing the conclusion that Egr1 is required for apoptosis.

A summary of the interactions between Egr1, p53, and the two major p73 subtypes at the transcriptional and protein levels is presented in Figure 8f. Our results indicate that p73 almost equals p53 as a physiologically effective inducer of apoptosis. In this interactive system the process of apoptosis can occur even in the absence of p53, if Egr1 and p73 are active. We conclude that all three interacting factors, Egr1, p53 and p73 are required for maximal induction of apoptosis in vivo and in vitro. More importantly, expression levels of each gene remain elevated for extended periods if two of the three are expressed together.

\section{Discussion}

Two important new findings are described in this paper. One is the interdependency on transcription factor Egr1 for the regulation of expression of p53 family members p53 and p73 in response to stress. In turn, proteins produced by each gene affect the others in feedback loops. Dependency on Egr1 for stimulatory effects in vivo was shown after genotoxic stress of 
mice, followed by analysis of RNA levels in tissues. No induction of p73 occurred in mice that are null for Egr1. The second finding is the interdependency that occurs through previously unrecognized EBS as well as newly recognized non-consensus p53RE contained in Egr1 and TP53 promoters. Of four putative p53BS in the Egr1 promoter, only two are active and bind p53 phosphorylated at S46 (Figure 7c). In contrast the S15-phospho-p53 form binds to the p53 promoter binding sites (Supplementary Figure S10). These p53RE (A2 and A3) are active, as proven by mutation of the sites. Similarly, we identified three new p53RE (called F, M and Z) in the p53 promoter (Figure 6d, Supplementary Figure S6C). Two of these sites with imperfect consensus sequences are transcriptionally active, while one with intact $C+G / C+G$ motifs is inactive. We show in Supplementary Data-S6C, that only the non-consensus $F$ and $M$ p53RE contain trinucleotide triplet repeats of CTG-CAG that form hairpin loops, which provide strong binding sites for p53 family members (30). The two active p53RE in TP53 promoter are upregulated by all members of the p53 family including p53, TAp73 and $\Delta$ Np73 (Figure $6 \mathrm{~b}$ ). The transactivating function of $\Delta \mathrm{Np} 73 \mathrm{a}$ (Figure 6e) requires the 13 amino-acid amino-terminal sequence, as a novel TAD, together with the PXXP domain (sequence 14-78). The responses of both Egr1 and TP53 promoters are similar for $\Delta \mathrm{Np} 73 \alpha$ and $\beta$ isoforms (Figures $5 \mathrm{a}$ and $6 \mathrm{~b})$, whereas in other studies only $\beta$ was active in upregulating $p 53$ target genes, ${ }^{25}$ suggesting that the specific sequence of the interacting p53RE on the promoter might play a crucial role. We conclude that the novel non-consensus p53RE in both the p53 and Egr1 promoters described here are specific for regulatory activity of $\Delta \mathrm{Np} 73$ isoforms.

The new active sites in all four promoters are responsible for interdependency of these genes and fine tuning of cellular responses to various stimuli. Mutational analyses of previously undetected p53BS in the responsive promoters, together with verification of the binding of the proteins to these REs by ChIP supports our conclusions. The interpretation of the time-course studies after ETO treatment is simplest in MCF7 cells which lack p73. The first peak of Egr1 protein is an early response, while the sustained Egr1 mRNA is likely brought about by high levels of stabilized p53 through the MDM2 pathway. ${ }^{26}$ This interpretation is supported by the maximal effect of RNAi-p53 (Figure 7a) during the time-course when the levels of active p53 protein are highest from 3 to $5 \mathrm{~h}$, at the same time when maximal binding to the p53 RE in the Egr1 promoter is found (Figure 7c) and preceding the second peak of Egr1 protein at $8-12 \mathrm{~h}$ (Figure 7b),

S46p-p53 binds to p53 RE on Egr1 promoter in U2OS cells whereas S15p-p53 binds to TP53 promoter (Supplementary Figure $\mathrm{S10C}$ ), indicating that post-translational forms of p53 have specific functions. We assume that ChIP analyses reveal which isoforms of $p 53$ are transcriptionally active, when these forms are bound to the promoters of interest. This may explain the sustained p53 mRNA and protein levels from 2 to $12 \mathrm{~h}$. It appears that several pathways contribute to the effects measured. Stability of p53 may also be sustained by the MDM2 pathway, but the results cannot show distinct peaks of activity because of the continuous feedback interactions and changes in levels, activities and molecular stabilities. Our results are consistent with the model of gene interrelationships shown in Figure 8f.

Athough Egr1 plays many roles in response to different stimuli, a major physiological response to increased Egr1 levels by genotoxic stress in most cell types is apoptosis. ${ }^{27,28}$ In U2OS cells (Figure 1a) a combination of Egr1, p53 and p73 gave the highest level of apoptosis. In keeping with this, Figure $8 \mathrm{~b}$ shows that all three RNAi species are effective in reducing apoptosis after ETO treatment and that combining RNAi to all three genes was required for maximal reduction of apoptosis. Importantly, this result was confirmed in Egr1 ${ }^{-1-}$ MEFs that do not express any of the three genes and are resistant to apoptosis (Figure $8 d-e$ ). We conclude that S20pp53 plays no role in the transcriptional activity measured here but both S15p-p53 and S20p-p53 participate in p53 stabilization and nuclear localization through the MDM2 pathway.

Egr1 and p53 could synergize to increase PTEN expression, ${ }^{29,30}$ which inhibits Akt, allowing retention of MDM2 in the cytoplasm. This in turn promotes p53 functions and sustains the sensitivity of cancer cells to chemotherapy. The synergism of Egr1 and p53 for transactivation of the same target genes such as PTEN is known (our unpublished data) and may also include $p 73$. The final result is a more rapid apoptotic endpoint rather than DNA repair or cell cycle arrest.

We noted earlier that p53 target genes overlap those of Egr1. ${ }^{31}$ The role of p53 in senescence, differentiation, apoptosis, growth control and DNA damage repair, echo similarly with those of Egr1..$^{5,6,19,32,33}$ We conclude from the present studies that transcriptional interdependence between Egr1 and p53/p73 largely explains these similarities. Other studies have reported changes in the stability of the proteins, ${ }^{34,35}$ in their binding to $\mathrm{p}^{300^{36}}$ or in changes in protein localization during apoptosis. ${ }^{37}$

Here, we have reported mainly on the transcriptional properties of the four gene products Egr1, TAp73, $\Delta$ Np73 and p53. We hypothesize that p73 is more important than p53 in stress responses in prostate cancer cells where Egr1 is highly expressed and p53 and PTEN are often inactive. Thus, the forecast ${ }^{38}$ that there must be 'a very tight relationship between the three members of the same family' is proved and extended here by the addition of Egr1 to the equation. These results have implications for the origins and progression of cancer.

\begin{abstract}
Materials and Methods
Cells and culture, antibodies. H4, MCF7, 293T, Saos2, U2OS cells were cultured in DME containing $10 \% \mathrm{FBS}$, penicillin, and streptomycin, at $37^{\circ} \mathrm{C}$ and $5 \%$ CO2. M12 metastatic human prostate cancer cells were cultured as described earlier. ${ }^{20}$ For ultraviolet-C (UV-C) irradiation $\left(40 \mathrm{~J} / \mathrm{m}^{2}\right)$ in a Stratalinker (Stratagene, La Jolla, CA, USA) as well as for mock treatment, the growth medium was aspirated and then replaced after treatment. Antibodies Egr1 (C-19), Egr1 (588), p53 (DO-1), p73 (E4), p73(S-20), p73 $\alpha(\mathrm{C}-17)$ were from Santa Cruz Biotechnology (Santa Cruz, CA, USA). E4 recognizes amino acids $1-80$ of human $p 73$ and $C-17$ reacts only to p73 $\alpha$. Antibodies to phosphorylated p53, Phospho-p53 (Ser 6, Ser15, Ser20 and Ser46) were from Cell Signaling Technology, Beverly, MA, USA. Antibody to p73 (Ab-2) (that recognizes all p73 isoforms), and $\triangle N p 73$ were from Oncogene Research Products (San Diego, CA, USA). Anti-(3-actin and anti-Flag M2 monoclonal antibodies were from Sigma (St Louis, MO, USA). Anti-HA (mouse lgG) was from Roche Applied Science (Indianapolis, IN, USA).
\end{abstract}

Mouse studies. Mice derived from two sources that are Egr1 null ${ }^{23,24}$ were used to determine the effect of gamma-radiation ( $5 \mathrm{~Gy}$ ) on gene expression 
measured by semi-quantitative RT-PCR, $2.5 \mathrm{~h}$ later. Tissues were rapidly dissected and placed in $0.5 \mathrm{ml}$ RNAeasy solution (Qiagen, Valencia, CA, USA). Total RNA was extracted and semi-quantitative RT-PCR was performed using $400 \mathrm{ng}$ total RNA as template using the Superscript One-step RT-PCR with Platinum Taq kit (Invitrogen, Carlsbad, CA, USA). Primers to measure p73, Egr1 and Cyclophilin (CPH) were used (Supplementary Data-S11). The amplified cDNAs were resolved on a $2 \%$ agarose gel. The two strains of KO mice behaved identically in this study.

Plasmids. Three genomic DNA fragments with sizes of 2458,1225 and $994 \mathrm{bp}$ corresponding to the promoter and its $5^{\prime}$-upstream regulatory sequences of TAp73, $\Delta N p 73$ and p53, respectively, were amplified from human genomic DNA using Advantage-GC Genomic Polymerase Mix Kit (BD Biosciences Clontech, Palo Alto, CA, USA) and subcloned into a luciferase reporter, pGL3-Basic vector, thus creating pGL3-TAp73, pGL3- $\Delta$ Np73 and pGL3-p53 (confirmed by sequencing).

The pGL3-Egr1 Luciferase reporter constructs and expression vector for pcDNA3-Flag-Egr1were made as described. ${ }^{20}$

Mutations were introduced by directed mutagenesis according to Quick-Change Multi Site-Directed Mutagenesis Kit (Stratagene, San Diego, CA, USA). All constructs were confirmed by sequencing. The mutation strategy was that $4 \mathrm{nt}$ of each p53RE or 3-4nt of each EBS (9 nt) were mutated and cloned into a restriction endonuclease site in order to identify the active binding sites.

We received many expression vectors from several researchers. Plasmids pCMV-neo-Bam-p53wt, were provided by B Vogelstein (Johns Hopkins University), pRC/CMV-p53wt from S Matsuzawa and pcDNA3.1-HA-hp53 from C Geisen, (both from The Burnham Institute). Plasmids pcDNA3-HA-TAp73a were provided by WG Kaelin (University of Toronto), pcDNA3-HA-TAp73 $\beta$ and pcDNA3-HA- $\Delta$ Np73a provided by Jean JY Wang, (University of California, San Diego). To generate pcDNA3-HA- $\triangle N p 73(3$, we replaced the fragment encoding C-terminal amino acids of pcDNA3-HA-TAp73 $\beta$ by excision of pcDNA3-HA- $\triangle$ Np73a with PmI/Xhol. The pcDNA3-HA-TAp73a $\Delta 1-62, \quad$ pcDNA3-HA-TAp73a $\Delta 1-127$, pcDNA3-HA$\Delta N p 73 a \Delta 1-13$ and pcDNA3-HA- $\Delta$ Np73a $\Delta 1-78$ were provided by $\mathrm{K}$ Yoshihara, Nara Medical University, Japan. Primer sequences used for cloning the promoters and for mutated promoters are given in the Supplementary Information.

Transfection and Luciferase reporter assays. For DNA transfection, we seeded 293T, M12, U2OS and MCF7 cells at a density of $8-10 \times 10^{5}$ into $60 \mathrm{~mm}$ dishes the day before transfection in order to achieve $75-95 \%$ confluence. Transfection was performed with Lipofectamine ${ }^{\mathrm{TM}} 2000$ (Invitrogen) following the instructions provided by the manufacturer, in a final volume of $1.5 \mathrm{ml}$ of DMEM medium with $10 \%$ FBS without antibiotics. Typically $2 \mu \mathrm{g}$ of DNA were mixed with $6 \mu \mathrm{l}$ of Lipofectamine. Cells were collected $24 \mathrm{~h}$ after transfection for immunoblotting.

For luciferase assays, we added $2-3 \times 10^{3} \mathrm{H} 4$ cells, $5-8 \times 10^{3} 293 \mathrm{~T}$ and Saos2 cells to each well of 96 -well plates 1 day before transfection. Transfection was performed with Lipofectamine ${ }^{\mathrm{TM}} 2000$ (Invitrogen). Typically $85 \mathrm{ng}$ of total plasmid DNA (40 ng of reporter construct, $40 \mathrm{ng}$ of the appropriate expression vector, plus $5 \mathrm{ng}$ of pRL-SV40 for Egr1 target test or $5 \mathrm{ng}$ of pRL-CMV for p53/p73 target test) were mixed with appropriate volume of Lipofectamine ${ }^{\mathrm{TM}} 2000$. Cells were lysed $24 \mathrm{~h}$ after transfection and luciferase activities were assessed using Dual-Luciferase ${ }^{\mathbb{R}}$ Reporter Assay System (Promega, Madison, WI, USA) and an EG\&G Berthold LB96P luminometer (PE Biosystem, Wellesley, MA, USA). Each data-point represents the mean-fold change compared to basic vector.

Light Cycler Quantitative RT-PCR. Total RNA was purified from cell lysates at different times after ETO addition ( $0,1,3,5,7$ and $11 \mathrm{~h})$. RNA purification and LightCycler QRT-PCR were performed as described previously. ${ }^{20}$ Specific primers for cyclophilin A, Egr1, p53, p73 are given in the Supplementary Data.

Immunoblot analysis. Cells were lysed in $50 \mathrm{mM}$ Tris- $\mathrm{HCl}$, pH7.4, $150 \mathrm{mM}$ $\mathrm{NaCl}, 1 \% \mathrm{NP}-40,1 \%$ sodium deoxycholate, $0.1 \%$ SDS and $1 \times$ complete protease inhibitor cocktail (Roche). Lysate $(22 \mu \mathrm{g})$ was separated on a NuPAGE 3-8\% TrisAcetate Gel (Invitrogen Co., Carlsbad, CA, USA) and analyzed by Western blotting. The membranes were probed with the appropriate antibodies.

Antibody-antigen complexes were detected using Amersham ECL or $\mathrm{ECL}^{+}$kit (Amersham Biosciences Corp, Piscataway, NJ, USA). Blots were photographed and quantified using Alpha Inotech Inc. equipment.

Chromatin immunoprecipitation. ChIP was performed as described previously ${ }^{39}$ with modifications. ${ }^{20}$ Cells were treated with ETO $(20 \mu \mathrm{g} / \mathrm{ml})$ for $2.5 \mathrm{~h}$
M12, (Figure 3c) or for $6 \mathrm{~h}$ (U2OS, Figures $4 \mathrm{c}, 5 \mathrm{c}$ and $6 \mathrm{c}$ ) before addition of $1 \%$ formaldehyde to crosslink proteins to the chromatin. After immunoprecipitation with specific p73, Egr1 or p53 antibodies or a non-immune IgG, the DNA fragments collected after sonication were purified and tested for the presence of a promoter using specific primers and PCR for 35 cycles. Primer sequences are given in Supplementary Data-S11.

RNA interference experiments. We transfected cells with GenEclipse ${ }^{\mathrm{TM}}$ control, p53 or Egr1 vector-based siRNA (Chemicon International) and SignalSilence ${ }^{\mathrm{TM}}$ p73 siRNA (Cell Signaling Technology) according to the protocol provided by the manufacturer. M12, MCF7 and U2OS cells were seeded into $60 \mathrm{~mm}$ dishes at a density of $8 \times 10^{5}, 5 \times 10^{5}$ and $5 \times 10^{5}$ cells, respectively, 1 day before transfection in order to achieve $75-95 \%$ confluence. At $24 \mathrm{~h}$ after transfection, ETO (Sigma, St Louis, MO, USA) was added at $20 \mu \mathrm{g} / \mathrm{ml}$ and cells were cultured for 24 or $48 \mathrm{~h}$. For Western-blots cells were collected at time $0,2,4,6,8$ and $12 \mathrm{~h}$ after ETO treatment.

Measurement of apoptosis. (a) Cells were treated with ETO and the percentage of dead cells was counted as Trypan Blue-stained cells together with total number of cells alive in triplicate dishes. (b) $\mathrm{Egr}^{+/+}$and ${ }^{-/-} \mathrm{MEFs}$ were fixed in methanol, 2 and $21 \mathrm{~h}$ after ETO treatment or untreated. Adhering cells were stained with Hoechst dye according to the manufacturers instructions (SigmaAldrich, Milwaukee, WI, USA), and the ratio of fragmented nuclei (apoptotic) to normal nuclei was counted using a Nikon epifluorescence microscope. Counts were averaged over 10 fields. Cells in the supernatant were also counted. An average of 700-1000 cells were counted per sample and the experiment was repeated once. Photographic records were also made (data not shown). For UV stimulation, the Trypan Blue method was used.

Acknowledgements. Egr1 ${ }^{+/+}$and Egr $^{-/-}$mice were kindly provided by $\mathrm{J}$ Milbrandt and N Mackman. We are grateful to $C$ Geisen and S Matsuzawa of the Burnham Institute for wt-p53 expression plasmids. p73 expression plasmids with deletions were kindly provided by $Y$ Tanaka and were derived from the original plasmid described in Laurenzi et al. ${ }^{40}$ We thank WG Kaelin and JJY Wang who provided valuable $p 73$ expression plasmids. We gratefully acknowledge the PHHS for grants funding these studies: post-doctoral Fellowship DAMD17-03-1-0028 (JY); R01 CA96949 (TM), R01 CA67888 and DAMD17-01-1-0005 (EDA); R01 CA102688 (VB) and R01 CA76173 (DM). We thank Shilpi Arora, Erkki Ruoslahti and Ze'ev Ronai for comments on the manuscript. The authors declare that they have no conflicting financial interests.

1. Sukhatme VP, Cao XM, Chang LC, Tsai-Morris $\mathrm{CH}$, Stamenkovich D, Ferreira PC et al. A zinc finger-encoding gene coregulated with $\mathrm{c}$-fos during growth and differentiation, and after cellular depolarization. Cell 1988; 53: 37-43.

2. Adamson ED, Mercola D. Egr1 transcription factor: multiple roles in prostate tumor cell growth and survival. Tumour Biol 2002; 23: 93-102.

3. Quinones A, Dobberstein KU, Rainov NG. The egr-1 gene is induced by DNA-damaging agents and non-genotoxic drugs in both normal and neoplastic human cells. Life Sci 2003; 72: 2975-2992.

4. de Belle I, Huang R-P, Fan Y, Liu C, Mercola D, Adamson ED. p53 and Egr-1 additively suppress transformed growth in HT1080 cells but Egr-1 counteracts p53-dependent apoptosis. Oncogene 1999; 18: 3633-3642.

5. Pignatelli M, Luna-Medina R, Perez-Rendon A, Santos A, Perez-Castillo A. The transcription factor early growth response factor-1 (EGR-1) promotes apoptosis of neuroblastoma cells. Biochem J 2003; 373 (Part 3): 739-746.

6. Nair P, Muthukkumar S, Sells SF, Han SS, Sukhatme VP, Rangnekar VM. Early growth response-1-dependent apoptosis is mediated by p53. J Biol Chem 1997; 272 : 20131-20138.

7. O'Farrell T J, Ghosh P, Dobashi N, Sasaki CY, Longo DL. Comparison of the effect of mutant and wild-type p53 on global gene expression. Cancer Res 2004; 64: 8199-8207.

8. Melino G, Lu X, Gasco M, Crook T, Knight RA. Functional regulation of p73 and p63: development and cancer. Trends Biochem Sci 2003; 28: 663-670.

9. Maisse $C$, Guerrieri $P$, Melino G. p73 and p63 protein stability: the way to regulate function? Biochem Pharmacol 2003; 66: 1555-1561.

10. Courtois $S$, de Fromentel $C C$, Hainaut $P$. p53 protein variants: structural and functional similarities with p63 and p73 isoforms. Oncogene 2004; 23: 631-638.

11. Ishimoto O, Kawahara C, Enjo K, Obinata M, Nukiwa T, Ikawa S. Possible oncogenic potential of DeltaNp73: a newly identified isoform of human p73. Cancer Res 2002; 62: 636-641. 
12. Stiewe T, Theseling CC, Putzer BM. Transactivation-deficient Delta TA-p73 inhibits $p 53$ by direct competition for DNA binding: implications for tumorigenesis. J Biol Chem 2002; 277: 14177-14185.

13. Zaika Al, Slade N, Erster SH, Sansome C, Joseph TW, Pearl M et al. DeltaNp73, a dominant-negative inhibitor of wild-type p53 and TAp73, is up-regulated in human tumors. J Exp Med 2002; 196: 765-780.

14. Flores ER, Tsai KY, Crowley D, Sengupta S, Yang A, McKeon F et al. $p 63$ and $p 73$ are required for p53-dependent apoptosis in response to DNA damage. Nature 2002; 416: 560-564.

15. Petrenko O, Zaika A, Moll UM. deltaNp73 facilitates cell immortalization and cooperates with oncogenic Ras in cellular transformation in vivo. Mol Cell Biol 2003; 23: 5540-5555.

16. Yang A, Walker N, Bronson R, Kaghad M, Oosterwegel M, Bonnin J et al. p73-deficient mice have neurological, pheromonal and inflammatory defects but lack spontaneous tumours. Nature 2000; 404: 99-103.

17. Moll UM, Slade N. p63 and p73: roles in development and tumor formation. Mol Cancer Res 2004; 2: 371-386.

18. Krones-Herzig A, Mittal S, Yule K, Liang H, English C, Urcis R et al. Egr1 acts as a tumor suppressor in vivo and in vitro via regulation of p53. Can Res 2005; 65: 5133-5143.

19. Krones-Herzig A, Adamson E, Mercola D. Early growth response 1 protein, an upstream gatekeeper of the p53 tumor suppressor, controls replicative senescence. Proc Natl Acad Sci USA 2003; 100: 3233-3238.

20. $\mathrm{Yu}$ J, de Belle I, Liang H, Adamson ED. Co-activating Factors p300 and CBP are transcriptionally cross-regulated by Egr1 in prostate cells, leading to divergent responses. Mol Cell 2004; 15: 83-94

21. Walter K, Warnecke G, Bowater R, Deppert W, Kim E. Tumor suppressor p53 binds with high affinity to CTG. CAG trinucleotide repeats and induces topological alterations in mismatched duplexes. J Biol Chem 2005; 280: 42497-42507.

22. Chen $\mathrm{X}$, Zheng $\mathrm{Y}$, Zhu J, Jiang J, Wang J. $p 73$ is transcriptionally regulated by DNA damage, p53, and p73. Oncogene 2001; 20: 769-774.

23. Lee SL, Sadovsky Y, Swirnoff AH, Polish JA, Goda P, Gavrilina G et al. Luteinizing hormone deficiency and female infertility in mice lacking the transcription factor NGFI-A (Egr-1). Science 1996; 273: 1219-1221.

24. Topilko P, Schneidermaunoury S, Levi G, Trembleau A, Gourdji D, Driancourt MA et al. Multiple pituitary and ovarian defects In Krox-24 (Ngfi-a, Egr-1)-targeted mice. Mol Endocrinol 1998; 12: 107-122.

25. Liu G, Nozell S, Xiao H, Chen X. DeltaNp73beta is active in transactivation and growth suppression. Mol Cell Biol 2004; 24: 487-501.
26. Alarcon-Vargas D, Ronai Z. p53-Mdm2 - the affair that never ends. Carcinogenesis 2002 23: $541-547$

27. Stuart JR, Kawai H, Tsai KK, Chuang EY, Yuan ZM. c-Abl regulates early growth response protein (EGR1) in response to oxidative stress. Oncogene 2005; 24: 8085-8092.

28. Nair VD, Yuen T, Olanow CW, Sealfon SC. Early single cell bifurcation of pro- and antiapoptotic states during oxidative stress. J Biol Chem 2004; 279: 2749427501.

29. Stambolic V, MacPherson D, Sas D, Lin $Y$, Snow B, Jang $Y$ et al. Regulation of PTEN transcription by p53. Mol Cell 2001; 8: 317-325.

30. Virolle T, Adamson ED, Baron V, Birle D, Mercola D, Mustelin T et al. The Egr-1 transcription factor directly activates PTEN during irradiation-induced signalling. Nat Cell Biol 2001; 3: 1124-1128.

31. Baron V, Adamson E, Mercola D. The transcription factor Egr1 is a direct regulator of multiple tumor suppressors including TGF $\beta 1$, PTEN, p53 and fibronectin. Cancer Gene Ther 2005; 65: 5133-5143.

32. Madden SL, Galella EA, Zhu J, Bertelsen AH, Beaudry GA. SAGE transcript profiles for p53-dependent growth regulation. Oncogene 1997; 15: 1079-1085.

33. Ahmed MM. Regulation of radiation-induced apoptosis by early growth response-1 gene in solid tumors (Review). Curr Cancer Drug Targets 2004; 4: 43-52.

34. Tsai KK, Yuan ZM. c-Abl stabilizes $\mathrm{p73}$ by a phosphorylation-augmented interaction. Cancer Res 2003; 63: 3418-3424.

35. Kramer S, Ozaki T, Miyazaki K, Kato C, Hanamoto T, Nakagawara A. Protein stability and function of $\mathrm{p} 73$ are modulated by a physical interaction with RanBPM in mammalian cultured cells. Oncogene 2005; 24: 938-944.

36. Zeng X, Li X, Miller A, Yuan Z, Yuan W, Kwok RP et al. The N-terminal domain of p73 interacts with the $\mathrm{CH} 1$ domain of $\mathrm{p} 300 / \mathrm{CREB}$ binding protein and mediates transcriptional activation and apoptosis. Mol Cell Biol 2000; 20: 1299-1310.

37. Aqeilan RI, Pekarsky Y, Herrero JJ, Palamarchuk A, Letofsky J, Druck T et al. Functional association between Wwox tumor suppressor protein and p73, a p53 homolog. Proc Natl Acad Sci USA 2004; 101: 4401-4406.

38. Melino G, De Laurenzi V, Vousden KH. p73: Friend or foe in tumorigenesis. Nat Rev Cancer 2002; 2: 605-615.

39. de Belle I, Mercola D, Adamson ED. Method for cloning in vivo targets of the Egrtranscription factor. Biotechniques 2000; 29: 162-169.

40. De Laurenzi V, Costanzo A, Barcaroli D, Terrinoni A, Falco M, Annicchiarico-Petruzzelli M et al. Two new p73 splice variants, gamma and delta, with different transcriptional activity. J Exp Med 1998; 188: 1763-1768.

\section{Supplementary Information accompanies the paper on Cell Death and Differentiation website (http://www.nature.com/cdd)}

